\title{
Urgences
}

\section{Annie Cohen-Solal, Sartre 1905-1980, Paris, Gallimard, 1985, 728}

p.

\section{Paul Chanel Malenfant}

Numéro 13, mars 1986

\section{Éclats d'atelier}

URI : https://id.erudit.org/iderudit/025255ar

DOI : https://doi.org/10.7202/025255ar

Aller au sommaire du numéro

\section{Éditeur(s)}

Urgences

\section{ISSN}

0226-9554 (imprimé)

1927-3924 (numérique)

Découvrir la revue

Citer ce compte rendu

Malenfant, P. C. (1986). Compte rendu de [Annie Cohen-Solal, Sartre 1905-1980, Paris, Gallimard, 1985, 728 p.] Urgences, (13), 122-123.

https://doi.org/10.7202/025255ar d'utilisation que vous pouvez consulter en ligne.

https://apropos.erudit.org/fr/usagers/politique-dutilisation/ 


\section{“ÉCRIRE AUJOURD'HUI, AU- toportraits d'écrivains sur fond de siècle", Autrement, Paris, no. 69, avril 1985, 253 p.}

Présentation soignée, recherche d'une certaine position d'avant-garde, parti pris pour les pratiques innovatrices, diversité des approches et éclectisme, Autrement est une revue française "branchée" qui interroge les phénomènes sociaux et culturels contemporains: danse, mode, homosexualité, publicité, couples, art, télévision, etc. Dans ce numéro mettant en scène l'écriture, une cinquantaine d'écrivain-e-s français et étrangers (entre autres: Sollers, Le Clézio, Anne Hébert, Meschonnic) et quelques artistes, musiciens et éditeurs nous font lire l'objet écrit et ses lignes de force (les revues littéraires, l'écriture et l'ordinateur, l'objet-livre, le métier d'écrivaine, le travail d'écriture, etc.). Fictions (prose et poésiel, textes de réflexion théorique, entrevues, en tout près de soixante-dix textes qui nous font entrer dans les coulisses de la fabrique d'écriture, côté cour et côté jardin, histoire de savoir un peu pourquoi et comment écrire aujourd'hui.

Marie Bélisle

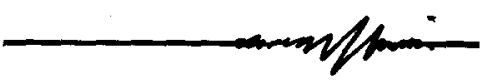

Shoshana Felman: La folie et la chose littéraire, coll. "Pierres vives", Paris, Seuil, 1978, 351 p.

Folie et littérature ont, depuis toujours, partie liée. En marge l'une de l'autre, elles s'appellent et s'excluent réciproquement. Cette relation pour le moins ambiguë a intéressé maints auteurs dont Shoshana Felman, Juive américaine, spécialiste de la littérature française. Dans La folie et la chose littéraire, elle nous livre son point de vue, théorique et critique, sur la folie de l'écriture et l'écriture de la folie.

Pour Felman, folie et littérature s'appréhendent comme une quête de l'étrange et de l'étranger, comme un cheminement à l'intérieur du langage. Ici, il ne s'agit plus de lire, mais de dé-lire, de dé-lier et de dé-régler. La folie semble une voie de la connaissance, un autre mode d'exploration de la différence instituée par le langage. Aussi, Felman nous ramène-t-elle, par le biais d'analyses du discours poétique, du roman et de la psychanalyse, à la frontière du champ littéraire, là où se jouent les répertoires d'une folie qui est "lieu commun", c'est-à-dire "lieu d'inciusion, dedans d'une culture" (p. 13). Son but principal sera donc d'ouvrir ce champ à la question de la folie, afin de penser autrement la littérature et les études littéraires. Ce but atteint, folie et littérature se rejoindraient pour s'éclairer mutuellement car, "s'il existe (...) quelque chose comme la chose littéraire, elle ne peut s'expliquer que par la folie (...) mais en vertu d'une irréductible résistance de la chose à l'interprétation" (p. 349).

La folie dont nous parle Felman, ce n'est ni celle que l'on enferme ni cette "hallucination des mots", mais plutôt une réponse de l'homme à la "question du mot".

Christiane Asselin

\section{Annie Cohen-Solal. Sartre 1905-1980, Paris, Gallimard, 1985, $728 \mathrm{p}$.}

Écrivain de la démesure, dont la vie de colosse infléchit le gigantisme et l'envergure de l'oenure, tel est le Sartre que nous 
raconte Annie Cohen-Solal dans un livre costaud, à l'écriture aussi fébrile et alerte que le parcours biographique qu'elle accompagne. Sartre: star? Certes, puisqu'il faut bien reconnaître ici le flamboiement d'une intelligence omniprésente à toutes les idées et à toutes les actualités de son époque. C'est donc avec une passion très documentée où le parti pris empathique ne se déleste jamais du souci de l'enquête, du fait vérifié avec minutie, que l'auteur retrace l'itinéraire d'une existence à la fois magistrale et admirablement marginale: celle de Poulou, l'enfant-roi chez son grand-père Schweitzer, celle de "l'écrivain qui a refusé le prix Nobel", celle du philosophe bourré de corydrane rédigeant la Critique de la raison dialectique, celle de l'amoureux naïf partagé entre son "Castor" (Simone de Beauvoir) et ses femmes. celle du gentil camarade écrivant pour Gréco "Dans la rue des blancs manteaux...", cette chanson que nous avons fredonnée en lisant La Nausée, enfin celle de l'homme public, à l'affût de toutes les causes, et dont l'audience internationale "Qu'en pense donc Sartre?" - aura sans doute investi l'histoire de ce siècle.

L'intérêt constant du livre de CohenSolal réside en ce que la biographe parvient à rendre une vie, "sur le vif", dans la turbulence même des actions de Sartre, dans la pulsion effrénée de son travail d'écriture; ainsi nous est-il constamment démontré comment les engagements sartriens (politiques, humanitaires, amoureux...) toujours reconduisent à la littérature cornme sens multiple de son existence. De cette manière, cette biographie vise moins à tracer le portrait d'une intimité ou d'une intériorité, à effectuer le bilan analytique d'une somme philosophique et littéraire, qu'à inscrire les interventions multiples d'un homme dans la ponctualité d'une Histoire et d'une Littérature. En ce sens, l'individu Sartre, malgré et avec la célébrité, les influences et les controverses, est affirmé dans son appartenance à la condition humaine; il retrouve alors cette discrétion intellectuelle et existentielle de tout être qui détient le courage de la pensée, de tous ceux qui ne sont pas des "salauds", cela même qu'il avouait dans les dernières phrases de son livre sans doute le plus écrit et le plus engagé, Les mots: "Si je range l'impossible Salut au magasin des accessoires, que reste-t-il? Tout un homme, fait de tous les hommes et qui les vaut tous et que vaut n'importe qui." Cette connivence du géant Sartre avec le commun des mortels, Cohen-Solal l'illustre avec toute la virtuosité de qui sait lire les livres et les hommes.

Paul Chanel Malenfant 